\section{Meteor at St. Thomas}

THE enclosed reached me from a meteorological correspondent in St. Thomas. The records of such phenomena must be rare; there may be something peculiar in this one; I therefore forward it to you. RAWSON RAWSON

Government House, Barbados, Dec. 30, 1872

"On November 30,1872 , at $8^{\mathrm{h}} 1 \mathrm{r}^{\mathrm{m}}$ P.M. a beautiful large me'eor was observed, which passed from west to east with great brilliancy, and exploded in the zenith in numerous little stars. It lasted about three seconds. A little after a rumbling noise, like distant thunder, was heard. It is reported by the watchman of the floating dock, which lies at present on the eastern beach of Long Bay in eight feet water, for repairs, that he was sler jing on the platform under an awning; he awoke from the heat and the strong light which passed close to him through the latt ce work; and some ashes fell on the dock which he found but did not collect, not knowing that it was of value. As is well krown, aerolites travel at the rate of 10,000 feet per second."

\section{Brilliant Meteor}

LAST night about I0.0, the moment after leaving the room in which I had been lecturing, at Wordsley, near Stourbridge, the ground about me was lighted up as by the sudden flash of a near lantern or the emergence of the full moon from a bank of cloud. On looking up at the sky, I saw a rocket-like object shooting down with a slightly zigzag motion like that of a fish, and leaving behind it a trail of mingled and mingling tints of green, purple, and yellow of nearly the semi-diameter of the moon. After a first thought about fireworks, I felt sure it was a meteor, and looked about for the constellations, so that I might be able to describe its path. The sky, however, was covered with clouds, only a star here and there being visible, and the moon, though easily seen, presenting a very hazy appearance. From inquiry at the Rectory as to the aspect of the schoolroom from which I had just come out, I judge that the course of the meteor must have been from north-west to west. When I first saw it, it vas about $40^{\circ}$ or $50^{\circ}$ above the horizon, and it traversed abcut halt the remaining space before disappearing, occupying, I estimate, about six seconds in doing so. Its path formed an angle of aibout $40^{\circ}$ with the horizon.

From the fact that the sky was covered with clouds and that the ineteor illuminated the ground with a light superior to that of tiie "half" moon shining at the time, I judge that the meteor v:as between the clouds and the earth. This nearness, would, of course, be an element in its great apparent size (which would be added to by the zigzag motion); and as it would also prevent its being seen at great distances and by many observers, I have, after some hesitation, penned this record of my very imperfect observations.

London, Feb. 4

\section{The Antinomies of Kant}

MY attention has been directed by a friend to an address by Prof. W. K. Clifford, in Macmillan's Magazine for this month, containing a curious misrepresentation of Kant's teaching, and therein an instructive instance of ultracrepidism. The professor remarks: "The opinion that at the basis of the natural order thare is something which we can know to be unreasonable to elude the process of human thought . . . is set forth first by Kant, so far as I know, in the form of his famous doctrine of the antinomies or contradictions, a later form of which I will endeavour to explain to you." "This doctrine," he continues, "has been dereloped and extended to the great successors of Kant, and this unreasonable, or unknowab'e, which is also called the absolute and the unconditioned, has been set forth in various ways as that which we know to be the true basis of all things."

I am sure I should not be allowed, in the columns of NATURE, sufficient space to point out in detail the misapprehensions in volved in these remarks. It is plain to me that Professor Clifford has approached the very difficult subject of Kant's Antinomies from the system of Sir William Hamilton. To start with Hamilton, however, is to be handicapped in the pursuit, and to augment the difficulties to be surmounted. In truth the doctrine Professor Clifford expounds is simply that of Hamilton; but Hamilton did not either develop or extend the Antinomies of Kant. He never understood them, but carved his little system out of a few splinters he gathered by the way. All Hamilton's characterisations of Kant are ludicrously false. This doctrine of the Antinomies does not answer, either, to Professor Clifford's touch. The Antithetic is not "unreasonable," nor does it "elude the processes of human thought ;" for, though it presents an unavoidable illusion, Kant has used reason, with matchless power and subtlety, to show that reason is master of the position, can solve every Antinomy, and can therefore guard against the very possibility of delusion. It is not any "natural order" of thought or things, that is found to be unreasonable, but the offence against common logic which is involved in every attempt to prove the thesis or antithesis of an antinomy. I refer all who care to see the thing for themselves to Kant's K. r. V., Element. ii. Th., ii. Abth., ii. Buch., 2 Hauptst., 7 Abschnitt: Kritische Entscheidung des kosmologischen Streits der Vernunft mit sich selbst : et seq.

Athenæum Club, Jan. 2I

C. M. INGLeby

\section{The Source of the Solar Heat}

IT gave me great pleasure to find that Captain Ericsson has taken the same views as myself with regard to the Source of the Solar Energy; but there is a certain part of his article in NATURE, vol. vi. p. 539, which I do not quite understand.

My views on this subject were sent to the Royal Astronomical Society, and were published in the Monthly Notices for April 1872 , where it was easily shown that if $\mathrm{E}$ be the total energy destroyed in a given time by the crushing-in of the sun's mass--

$$
\mathrm{E}=\frac{4}{5} \pi g_{0} \rho z_{0} r_{0}^{3}
$$

where $g_{0}$ is the force of gravity at the sun's surface,

$\rho$ the density, supposed constant,

$r_{o}$ the sun's radius,

$z_{0}$ the contraction of that radius in the given time; all corresponding to the present epoch.

To find $z_{0}$ we must express $\mathrm{E}$ in thermal units by means of the dynamical theory of heat, and equate the result to the total amount of heat radiated by the sun; and it is easy to show that $z_{0}$ must be I29 ft. per annum; and since Caplain Ericsson finds the eoritraction to be I2I ft., we are so jai in agreement.

But $\frac{4}{3} \pi \rho r_{0}^{3}$ is the mass of the surn, and $g$ varies inversely as $r_{0}^{2}$, hence we may write

$$
\frac{E=C Z}{R^{2}}
$$

where $C$ is a constant, and $R, Z$, the values of the radius ard of the contraction at any other epoch of time. Now there is no connection between $Z$ and $R$; if $Z$ varies as $R^{2}$, then $E$ is constant ; if $Z$ varies as $R$, which I believe to be the most probable assumption, then $\mathrm{E}$ varies inversely as $R$, and the total solar radiation must be slowly increasing; but I see no reason whatever for supposing that $Z$ varies directly as $R^{4}$, so that the solar radiation must be diminishing in proportion to the square of the sun's radius.

Jamaica

MaXWELl Hall

\section{The Twinkling of the Stars}

THE phenomenon observed and described by G. F. Burder in NATURR of Jan. 23, p. 222, does not, as I understand it, account in any way for the twinkling of stars, seeing that, by means of any two lights (gas lamps for instance) at the distance of a few hundreds of yards, the same effect may be observed, and this quite irrespective of the angle at which they are placed wich reference to the horizon or the "blind spot" of the observer's eye.

ThOS. HaWkSLEY

\section{Meteorological Cycles}

THE following observation may possess some interest in connection with the subject of recurring meteorological cycles. It is found at the conclusion of Mr. Consul Wallis's report on the trade and commerce of Costa Rica for I867, dated June I, I 868 (Parliamentary Papers for 1868.69, vol. lix. p. 520) :- "In the state of the public health there is a marked and satisfactory im. provement to report. No reason can be assigned here for the large number of epidemic disorders which have afflicted this country for the last ten years and since the visitation of the cholera, nor for the improvement which took place in the cleventh year."

London, Jan. 2
R. G. 